\title{
Separation of Electrolytic Reduction Product from Stainless Steel Wire Mesh Cathode Basket via Salt Draining and Reuse of the Cathode Basket
}

\author{
Eun-Young Choi, Jeong Lee, Dong Hyun Heo, and Jin-Mok Hur \\ Korea Atomic Energy Research Institute, Daedeok-daero 989-111, Yuseong-gu, Daejeon 34057, Republic of Korea \\ Correspondence should be addressed to Eun-Young Choi; winikjist@naver.com
}

Received 4 April 2017; Revised 27 August 2017; Accepted 6 September 2017; Published 8 October 2017

Academic Editor: Mark Deinert

Copyright (c) 2017 Eun-Young Choi et al. This is an open access article distributed under the Creative Commons Attribution License, which permits unrestricted use, distribution, and reproduction in any medium, provided the original work is properly cited.

\begin{abstract}
We demonstrated that the metallic product obtained after electrolytic reduction (also called oxide reduction (OR)) can be simply separated from a stainless steel wire mesh cathode basket only by using a salt drain. First, the OR run of a simulated oxide fuel $(0.6 \mathrm{~kg} / \mathrm{batch})$ was conducted in a molten $\mathrm{Li}_{2} \mathrm{O}-\mathrm{LiCl}$ salt electrolyte at $650^{\circ} \mathrm{C}$. The simulated oxide fuel of the porous cylindrical pellets was used as a cathode by loading a stainless steel wire mesh cathode basket. Platinum was employed as an anode. After the electrolysis, the residual salt of the cathode basket containing the reduction product was drained by placing it at gas phase above the molten salt using a holder. Then, at a room temperature, the complete separation of the reduction product from the cathode basket was achieved by inverting it without damaging or deforming the basket. Finally, the emptied cathode basket obtained after the separation was reused for the second OR run by loading a fresh simulated oxide fuel. We also succeeded in the separation of the metallic product from the reused cathode basket for the second OR run.
\end{abstract}

\section{Introduction}

The recycling of used fuel is a crucial issue for the sustainable use of nuclear energy. Pyroprocessing technology has attracted considerable interest in terms of recycling the used oxide fuels from nuclear power plants and using them as fuels for fast reactors. Through the integrated unit processes of pyroprocessing, the used oxide fuel is electrochemically reduced to metallic form and uranium (U), and transuranic (TRU) elements are recovered from the metallic product. Then, the metallic U/TRU product is provided for the metal fuel of the sodium-cooled fast reactor. The key unit processes of pyroprocessing are the electrolytic reduction (also called oxide reduction (OR)) and the electrorefining (ER) [1-8].

In the OR process as a front end process of pyroprocessing, the used oxide fuel contained in a permeable cathode basket is electrochemically reduced to metal in molten $\mathrm{Li}_{2} \mathrm{O}-\mathrm{LiCl}$ salt at $650^{\circ} \mathrm{C}\left(\mathrm{MO}_{2}+4 \mathrm{e}^{-} \rightarrow \mathrm{M}+2 \mathrm{O}^{2-}\right)$. Simultaneously, the oxygen ions $\left(\mathrm{O}^{2-}\right)$ are oxidized to yield oxygen $\left(\mathrm{O}_{2}\right)$ gas on the platinum $(\mathrm{Pt})$ anode $\left(2 \mathrm{O}^{2-} \rightarrow \mathrm{O}_{2}+\right.$ $4 \mathrm{e}^{-}$. The overall reaction involves the decomposition of $\mathrm{MO}_{2}$ to $\mathrm{M}$ and $\mathrm{O}_{2}\left(\mathrm{MO}_{2}=\mathrm{M}+\mathrm{O}_{2}(\mathrm{~g})\right)$ [9-19]. Next, during the ER process, the actinides in the reduction product obtained after OR are anodically dissolved into molten $\mathrm{LiCl}-\mathrm{KCl}$ salt at $500^{\circ} \mathrm{C}\left(\mathrm{M} \rightarrow \mathrm{M}^{3+}+3 \mathrm{e}^{-}\right)$. Simultaneously, highly pure $\mathrm{U}$ is collected onto a solid cathode $\left(\mathrm{U}^{3+}+3 \mathrm{e}^{-} \rightarrow \mathrm{U}\right)[20-$ 22]. Then, transuranic elements are recovered by employing a liquid cadmium cathode $\left(\mathrm{M}^{3+}+3 \mathrm{e}^{-} \rightarrow \mathrm{M}\right)[23,24]$.

Typically, a stainless steel (STS) wire mesh is used as the permeable basket containing the fuel in both OR and ER processes. The reduction product obtained after the OR process is then used as an anode in the ER process by loading it in a new STS wire mesh basket $[19,25]$. Thus, the separation of the reduction product from the OR cathode basket is required. However, it is not easy to separate the reduction product obtained after the OR from the STS wire mesh cathode basket at ambient temperature without damaging or deforming the basket because the residual salt in the basket is frozen. In our previous study [26], we performed a series of pyroprocessing steps consisting of OR, OR salt distillation, ER, and ER salt distillation using a single STS 


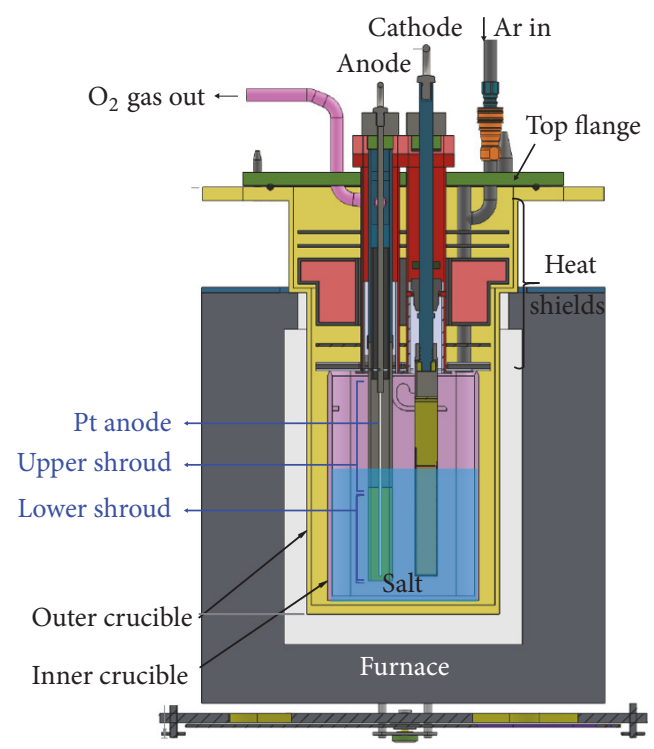

Figure 1: Drawing of the OR apparatus used in this study.

wire mesh basket without unloading and loading the fuel. Salt distillation at high temperature $\left(800-950^{\circ} \mathrm{C}\right)$ was performed to remove the residual salt of the OR and ER products from the STS wire mesh basket. We observed damage in the used STS wire mesh basket such as the spalling and desorption of the U-Fe layer. The damage was caused by the reaction between the metallic $U$ and Fe in the STS of the basket during the salt distillation process. Therefore, the present study was motivated by the results obtained from the previous study.

Here, we demonstrated that the reduction product obtained after the OR can be readily separated from the STS wire mesh cathode basket only through the use of a salt drain; then, the emptied basket can be further reused for a new OR run. The first OR run of a simulated oxide fuel (simfuel, $0.6 \mathrm{~kg} / \mathrm{batch}$ ) was conducted in $5 \mathrm{~kg}$ of molten $\mathrm{Li}_{2} \mathrm{O}-\mathrm{LiCl}$ salt at $650^{\circ} \mathrm{C}$. After the completion of the first OR run, the residual salt of the cathode basket was drained by placing it at gas phase above the salt using a holder. Then, at ambient temperature, the complete separation of the reduction product from the cathode basket was achieved by inverting it without damaging or deforming the basket. Finally, the emptied cathode basket, which was achieved after the separation, was reused for the second OR run by loading fresh simfuel. We also succeeded in separating the reduction product from the reused cathode basket for the second OR run.

\section{Experimental Procedures}

The OR apparatus was installed in a high-purity argon atmosphere glove box, where the concentrations of the moisture and $\mathrm{O}_{2}$ were maintained at less than $1 \mathrm{ppm}$ and $10 \mathrm{ppm}$ or less, respectively. Figure 1 shows a drawing of the OR apparatus used in the present study. It consists of the furnace, the outer STS crucible, the inner STS crucible, the top flange, and the electrodes (containing the cathode and the anode). The crucibles were placed in the furnace. The inner crucible $(165 \mathrm{~mm} \times 165 \mathrm{~mm} \times 250 \mathrm{mmH})$ contains the OR salt, and the outer crucible protects the inner crucible. As the OR electrolyte, $1.5 \mathrm{wt} . \%$ of $\mathrm{Li}_{2} \mathrm{O}$ (99.5\% purity, Alfa Aesar)- $\mathrm{LiCl}$ (99\% purity, Alfa Aesar) salt of $5 \mathrm{~kg}$ was used. Thermal dehydration of $\mathrm{LiCl}$ was conducted before use by heating to a temperature of $650^{\circ} \mathrm{C}$ at a linear rate of $0.5^{\circ} \mathrm{C} / \mathrm{min}$ under reduced pressure ( $<1$ Torr) and maintaining it for $6 \mathrm{~h}$ before cooling. The flange is located at the top of the crucibles to prevent heat loss and to fix the electrodes for immersion into the salt [27].

Figures 2(a-1) 2(a-4) show images of the cathode used in this study. It was manufactured by assembling the nickel (Ni) conductor containing an alumina $\left(\mathrm{Al}_{2} \mathrm{O}_{3}\right)$ insulator (Figure 2(a-1)) and the basket $(75 \mathrm{~mm} \times 25 \mathrm{~mm} \times 204 \mathrm{mmH}$ ) made of 5-ply layer (Poroplate ${ }^{\circledR}$ ) STS wire meshes. The rectangular cathode basket (Figure 2(a-4)) for the loading of the simfuel was fabricated by welding the STS wire meshes of the 5-ply layers (30-325-40-20-16 meshes, Poroplate). It should be noted that all surfaces of the cathode basket, including the walls of the side (Figure 2(a-2)) and the bottom (Figure 2(a-3)), were made of the permeable STS wire meshes, except for the welds, for efficient salt draining after the OR. The detailed specifications of the meshes are listed in Table 1. It was produced by sintering multiple layers into a single piece (total thickness of $1.9 \mathrm{~mm}$ ). At the center of the cathode basket, the electrical conductor was brought into contact with the simfuel at the center of the basket (Figure 2(a-4)). The cover shown in Figure 2(a-4) was used to prevent the electrical contact resistance by an evaporated $\mathrm{LiCl}$ salt.

The surrogate oxides and their mass fraction concentration for the composition of the simfuel are listed in Table 2. The simfuel is composed of $\mathrm{UO}_{2}$, rare earth oxides, noble metals, and salt-soluble fission products. The porous simfuel with the cylindrical shape shown in Figure 3(a) was prepared by mixing $\mathrm{UO}_{2}$ powder and surrogate oxide powders followed by pelletizing under 200-500 MPa and sintering at $1450^{\circ} \mathrm{C}$ for $24 \mathrm{~h} \mathrm{[28].} \mathrm{Its} \mathrm{density} \mathrm{and} \mathrm{size} \mathrm{were}$ $4.43 \sim 4.87 \mathrm{~g} / \mathrm{cm}^{3}$ and $\varnothing 6.1 \mathrm{~mm} \times 7.0 \mathrm{mmH}$, respectively.

The anode assembly consists of the $\mathrm{Pt}(40 \mathrm{~mm} \times$ $200 \mathrm{mmH} \times 3 \mathrm{~mm}$ ) connected to the electrical conductor and the metal shroud. The anode shroud consisted of a lower porous shroud made of the same material as that of the cathode basket and an upper nonporous shroud (Figure 1). $\mathrm{Ni}$ was used as the material for the upper nonporous shroud, and thin (thickness of $3 \mathrm{~mm}$ ) Pt was lined on its inner surface. $\mathrm{Li}-\mathrm{Pb}$ alloy $(32 \mathrm{~mol} \% \mathrm{Li})$ in porous magnesia $(\mathrm{MgO}, 0.5 \mathrm{~mm}$ ID) was used as the reference electrode.

The first OR was conducted using a $1.5 \mathrm{wt} . \% \mathrm{Li}_{2} \mathrm{O}-\mathrm{LiCl}$ salt at $650^{\circ} \mathrm{C}$, with the STS wire mesh cathode basket containing simfuel of $0.68 \mathrm{~kg}$. A constant voltage was applied using an external power supply (Agilent Model 6671A) between the cathode and the Pt anode. The cathode potential was monitored using the $\mathrm{Li}-\mathrm{Pb}$ reference electrode. During the OR, $\mathrm{O}_{2}$ gas was continuously exhausted using a pump from the upper end of the shroud to the $\mathrm{O}_{2}$ gas outlet (Figure 1), through the pipe connected to the cold trap installed outside the Ar glove box. After the termination of the first OR run, the residual salt of the cathode basket was drained by placing it at gas phase above the salt using a special holder for 
TABLE 1: Specifications of various STS wire meshes in the cathode basket used in this study.

\begin{tabular}{lccc}
\hline Mesh number & Opening size $[\mu \mathrm{m}]$ & Percentage of open area [\%] & Wire thickness $[\mu \mathrm{m}]$ \\
\hline 16 mesh & 1130 & 50 & 450 \\
20 mesh & 864 & 46 & 400 \\
30 mesh & 535 & 41 & 305 \\
40 mesh & 381 & 38 & 250 \\
100 mesh & 140 & 36 & 100 \\
325 mesh & $40-43$ & 30 & 35 \\
\hline
\end{tabular}

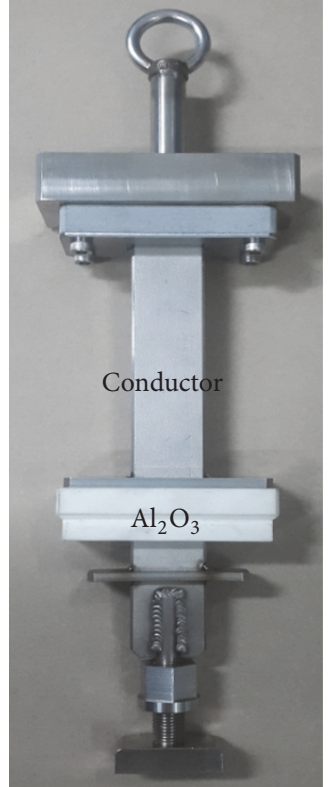

$(\mathrm{a}-1)$

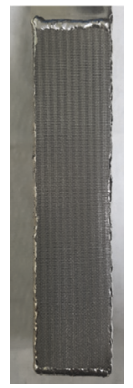

$(\mathrm{a}-2)$

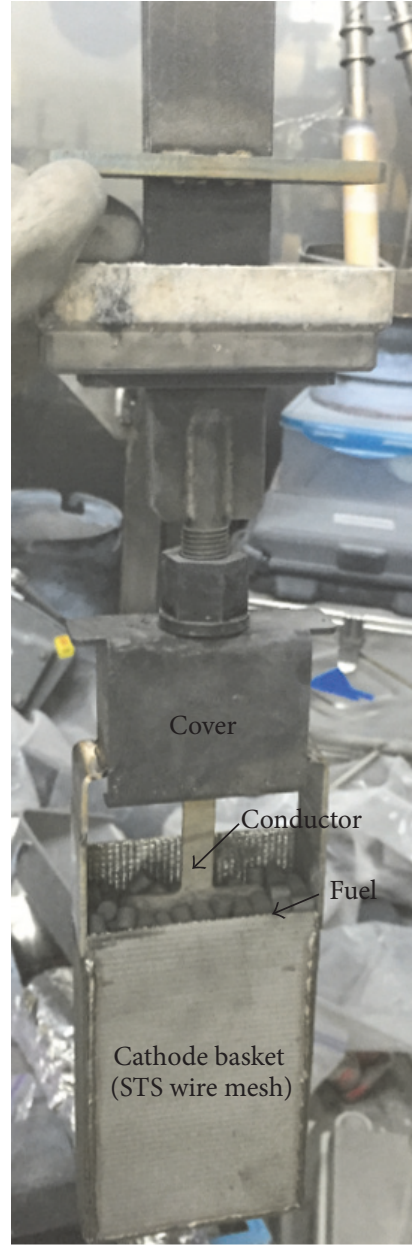

$(\mathrm{a}-4)$

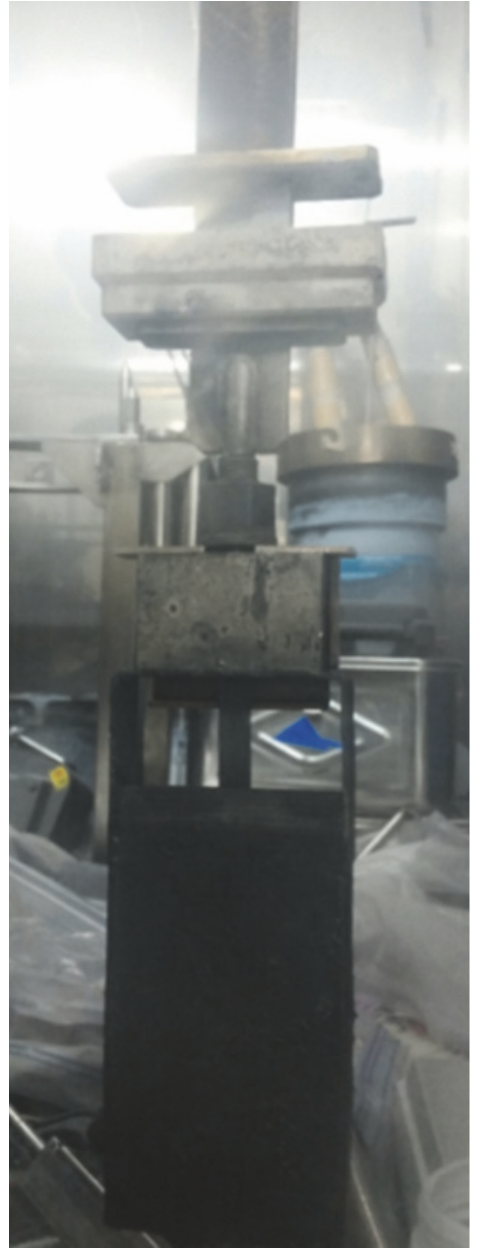

(b-1)

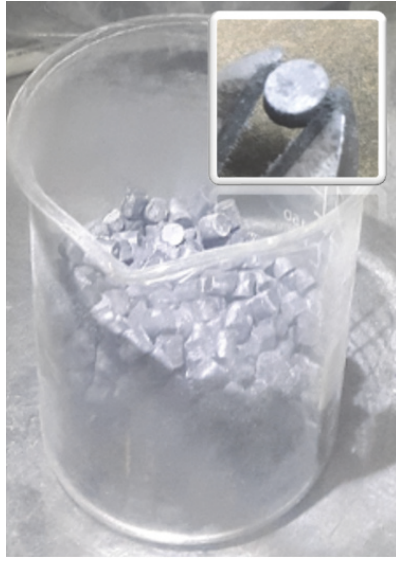

(b-2)

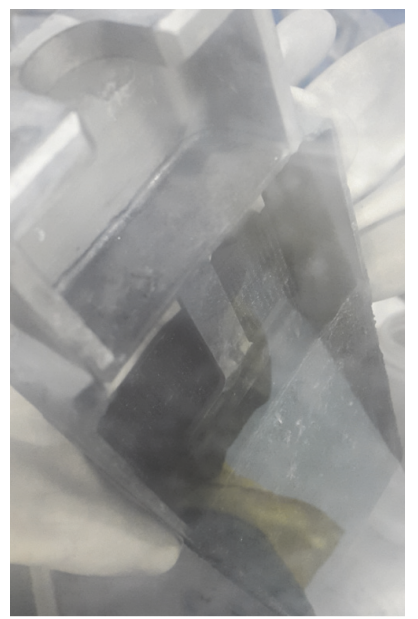

$(b-3)$

Figure 2: Images of the cathode before the OR (a-1) Ni conductor containing $\mathrm{Al}_{2} \mathrm{O}_{3}$ insulator, (a-2) side view and (a-3) bottom view, (a-4) the assembly, (b-1) the cathode basket used after the OR, (b-2) the separated reduction product from the basket, and (b-3) the emptied basket after the separation.

$24 \mathrm{~h}$ (Figure 4(a)). As shown in Figure 4(b), a holder was used on top of the flange to fix the cathode basket in place on the gas phase. During the salt drain, the temperature above the salt at $650^{\circ} \mathrm{C}$ where the cathode was located was measured by adjusting the height of a thermocouple in the vertical direction. After the salt drain, the cathode basket was removed from the OR apparatus and cooled at ambient temperature in the Ar glove box. The extent of reduction of the reduced simfuel was chemically determined by separating the metal and oxide phases in the reduced fuel sample, as described in the literature [19]. The salt samples obtained were subjected to elemental analysis using inductively coupled plasma-atomic emission spectroscopy (ICP-AES, JP Ultima$2 \mathrm{C}$, Jovin Yvon). The amount of the residual salt in the reduction product was determined by comparing the weight of the reduction products after water rinsing and subsequent drying with the weight before the treatment. The second OR run and the subsequent salt drain process were also performed in a similar manner to the first OR and salt drain processes. The emptied STS wire mesh basket obtained after 


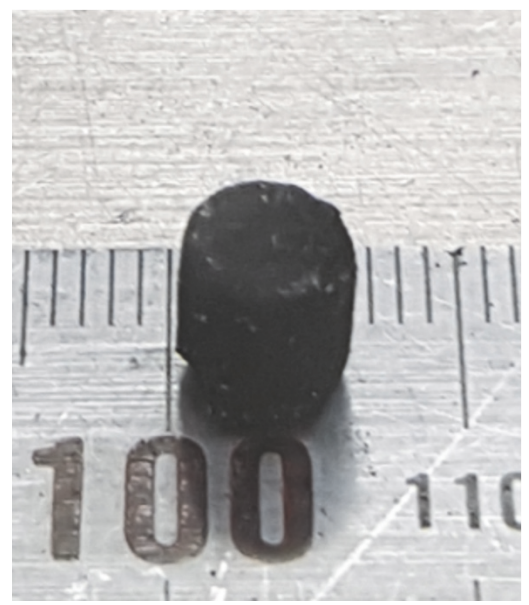

(a)

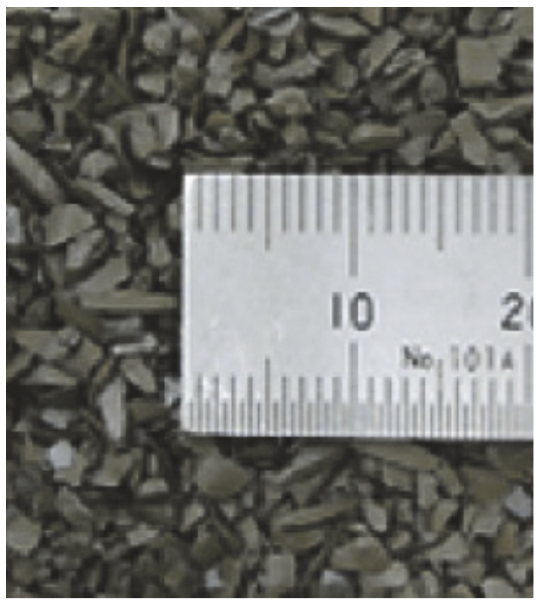

(b)

FIGURE 3: Images of the simfuel used in (a) the present study and (b) the previous study [29] (the minimum unit of the scale is $1 \mathrm{~mm}$ ).

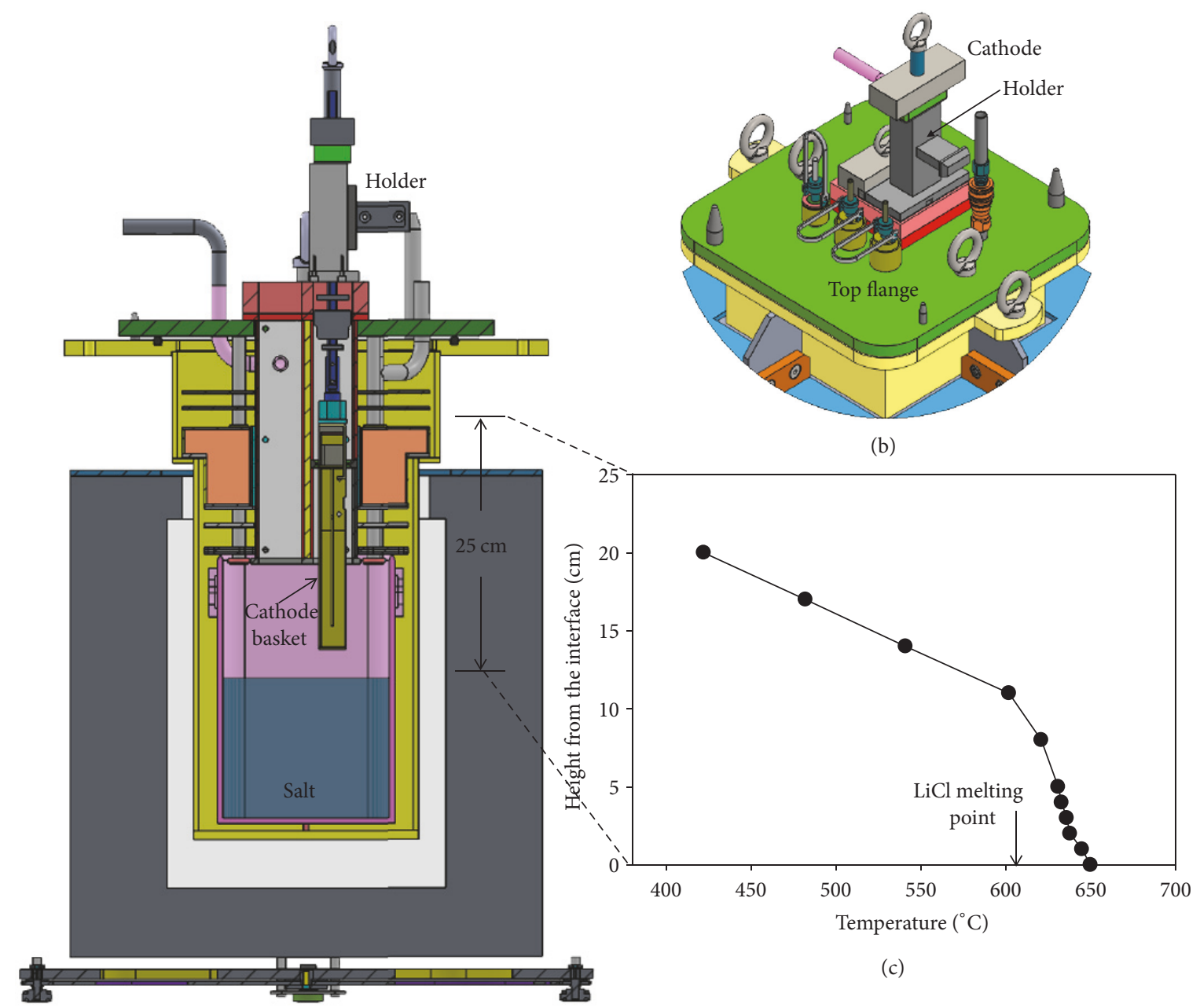

(a)

FIGURE 4: The salt draining process of the cathode basket after the OR: drawing of (a) the side view, (b) the top view, and (c) the vertical temperature distribution around the cathode basket. 


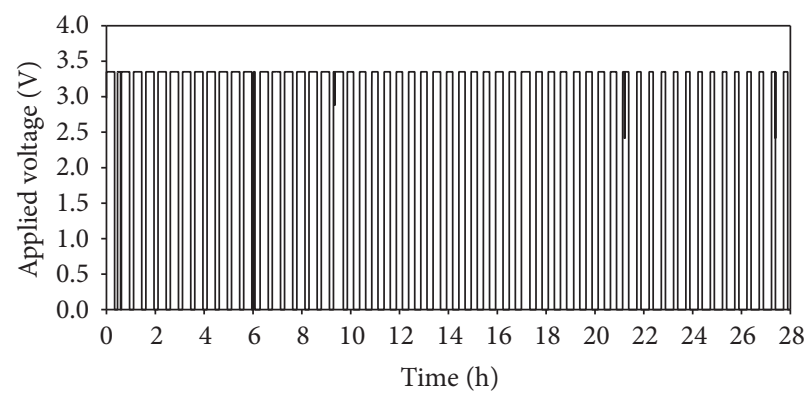

(a)

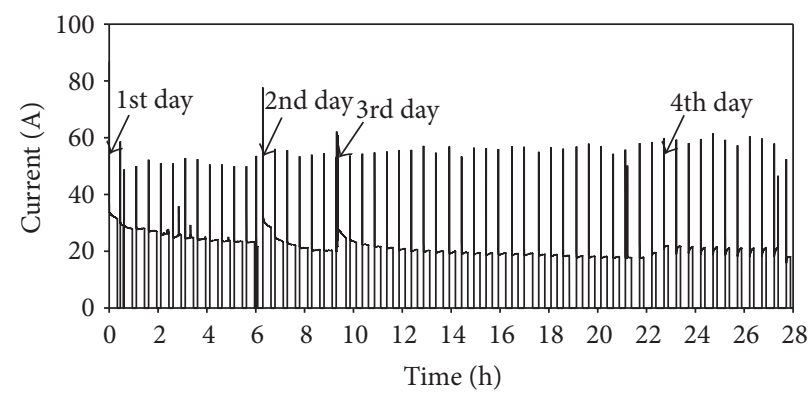

(b)

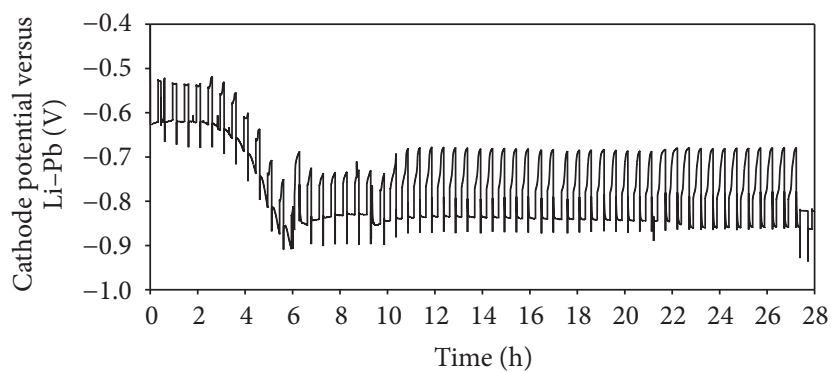

(c)

FIgURE 5: Diagrams from the first OR run: (a) the applied voltage versus time, (b) the response current versus time, and (c) the cathode potential versus time.

the second OR and the subsequent salt drain was examined by means of scanning electron microscopy (SEM, Hitachi, SU-8010) and energy dispersive X-ray (EDX) spectrometer (Horiba, EX-250 X-max).

\section{Results and Discussion}

The first $\mathrm{OR}$ run was performed in a molten $\mathrm{Li}_{2} \mathrm{O}$ (1.5 wt.\%)- $\mathrm{LiCl}$ salt at $650^{\circ} \mathrm{C}$ by applying a constant voltage between the anode and the cathode containing the simfuel of $0.68 \mathrm{~kg}$. The operation for the first OR was distributed over four days. In total, approximately $28 \mathrm{~h}$ (including both voltage on and off time) were required for the completion of the first OR operation. In Figure 5, the electrolysis results are presented by merging the results obtained for four different days. When $3.35 \mathrm{~V}$ of the cell voltage was applied by using the power supply (Figure 5(a)), the potential between the tops of the anode and cathode measured using a portable multimeter was 3.15-3.17 V due to the voltage drop between the power supply installed outside the glove box and the OR apparatus installed inside the glove box. As shown in Figure 5(b), the response current was 20-30 A. The average current density was approximately $0.26 \mathrm{~A} / \mathrm{cm}^{2}$ for $89.2 \mathrm{~cm}^{2}$ of the anode surface area immersed in the salt. A slight increase in the current was observed at the initial time $(0 \mathrm{~h}, 6.2 \mathrm{~h}, 9.5 \mathrm{~h}$, and $23 \mathrm{~h}$ in Figure 5(b)) of each operation day. The cathode was maintained at a potential lower than $-0.6 \mathrm{~V}$, at which $\mathrm{UO}_{2}$ is reduced [29]. Unexpectedly, the shift of the cathode potential towards higher negative values occurred within the initial $6 \mathrm{~h}$; then, any significant shift was not observed. The cause for this shift of the cathode potential is still not clear. It is presumed that the potential difference itself between the cathode and the $\mathrm{Li}-\mathrm{Pb}$ reference electrode did not change; the difference may be due to a change in $\mathrm{Li}-\mathrm{Pb}$, such as its oxidation.

After the completion of the first OR, the cathode was raised in a vertical direction so that it was positioned in the gas phase above the salt (Figure 4(a)) and its conductor was out of the top flange and then the holder was fixed in the conductor position (Figure 4(b)). The residual salt drain of the cathode basket was performed by maintaining the above-described position for $24 \mathrm{~h}$. After the salt draining, the cathode was removed from the OR apparatus and was then cooled down to ambient temperature in the Ar glove box (Figure 2(b-1)). Then, an attempt was made to drop the reduction product in the basket by inverting the cathode. Surprisingly, most of the reduction products were successfully separated from the cathode basket, as shown in Figure 2(b-2). Although several pellets of the reduction product remained on the bottom of the basket, they could be separated from the basket even with a slight physical impact. Figure 2(b-3) shows the emptied STS wire mesh basket after the separation. As presented in the inset image of Figure 2(b-2), the crosssection of the separated reduction product exhibits a metallic grey color, unlike the brown color of the simulated oxide fuel (before use). This color change indicates the successful OR (from $\mathrm{UO}_{2}$ in simfuel to $\mathrm{U}$ metal). The extent of $\mathrm{U}$ metal, which was determined through chemical analysis, was $99.5 \%$. The extents of the rare earths and noble metals were $\sim 25 \%$ and $\sim 99.5 \%$, respectively. The amount of residual salt in the reduction products, measured at random, was found to be less than 5 wt.\%.

The efficiency of salt draining can be attributed to the following reasons. The first reason is because of the use of the cathode basket only made of the permeable STS wire mesh. 


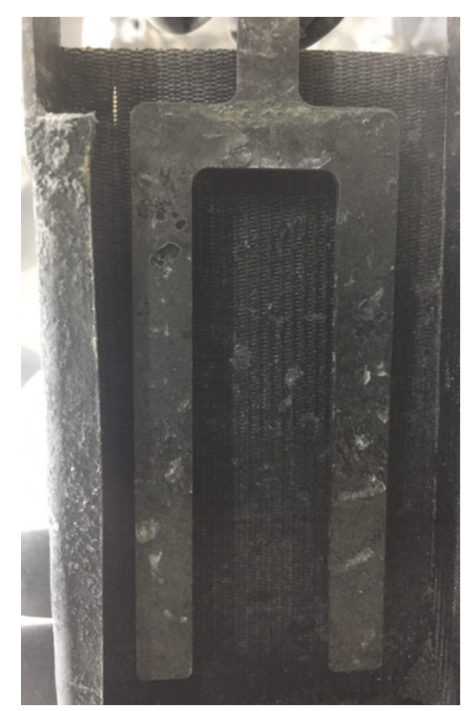

(a)

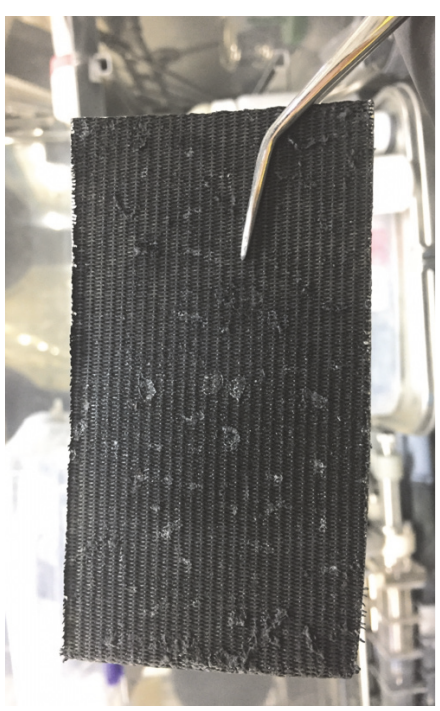

(b)

FIGURE 6: Images of the reused cathode basket after the second OR and the subsequent fuel separation via salt draining: (a) inside view and (b) its inner surface of the STS wire mesh.

As shown in Figures 2(a-2)-2(a-4), the cathode basket used is only made of the porous material (STS wire mesh) without using a nonporous material. As presented in Table 1, the open area of 325 mesh of the STS wire meshes used for the cathode basket is $30 \%$. Hence, both the side wall (Figure 2(a-2)) and the bottom wall (Figure 2(a-3)) of the cathode basket are porous, which allows the drain of the salt at the liquid state. Most of the residual salt was drained through the open area of the STS wire mesh cathode basket and dropped into the lower bulk $\mathrm{Li}_{2} \mathrm{O}-\mathrm{LiCl}$ salt during the draining process.

The second reason is because of the low surface area of the used cylindrical porous pellets with the size of $\varnothing 6.1 \mathrm{~mm}$ $\times 7.0 \mathrm{mmH}$ (Figure 3(a)). In our previous study [30], we had conducted OR in a $1 \mathrm{~kg} / \mathrm{batch}$ apparatus using a smaller crushed pellet (Figure 3(b)) which had the size of 1-4 mm and density of $10.67 \mathrm{~g} / \mathrm{cm}^{3}$. We made an attempt to separate the reduction product from the cathode basket through the salt drain similar to the method used in the present study (the data on the residual salt were not reported in the previous study). Despite achieving a low amount of residual salt (less than 5 wt.\%), the reduction products were not separated from the cathode basket as in the present study. This contrast resulted from the difference in surface area of the used fuels. The surface areas of the fuels used in the present and the previous studies were simply calculated by considering their respective densities and sizes. In the case of the small crushed pellets used in the previous study, it was assumed that the longest size in length and width was $4 \mathrm{~mm}$ and $1 \mathrm{~mm}$, respectively, and that they were shaped as small rugby balls; however, their actual shape was random, with a size of 1-4 $\mathrm{mm}$. The calculation results revealed that the total surface area of the cylindrical porous pellets used in the present study was $0.204 \mathrm{~m}^{2} / \mathrm{kg}$, whereas that of the small crushed pellets used in the previous study was $0.453 \mathrm{~m}^{2} / \mathrm{kg}$. Therefore, we believe that the low surface area of the cylindrical pellets was beneficial to the separation of the reduction products because the contact area between the pellets or between the pellets and the surface of the STS wire mesh cathode basket was relatively small; thus, the amount of residual salt on the contact surface was also small.

The third reason is the high temperature of the cathode basket maintained during the salt draining. Figure 4(c) shows the vertical temperature distribution above the salt at $650^{\circ} \mathrm{C}$, where the cathode was located during the salt draining. The bottom half of the cathode basket was located at a position where the temperature was $605 \sim 650^{\circ} \mathrm{C}$, which was higher than the $\mathrm{LiCl}$ melting point $\left(605^{\circ} \mathrm{C}\right)$. The temperature at the top of the cathode basket decreased to $450^{\circ} \mathrm{C}$. It is notable that, after cooling, even the reduction products located at the upper position of the cathode basket were well separated from it, despite the fact that the upper half was maintained below the LiCl melting point. This result implies that a significant amount of residual salt located near the top of the basket was removed by gravity downward to flow down quickly as soon as the cathode basket was raised from the salt. Moreover, the residual salt located near the bottom of the basket was drained outside the cathode basket in a liquid state, while maintaining a temperature above the melting point.

The emptied cathode basket achieved after the first OR run followed by the salt draining was subjected to the second OR run. After the fresh simfuel of $0.67 \mathrm{~kg}$ was loaded in the basket, the electrolysis and the subsequent salt drain were performed in a manner similar to that of the first OR. Similar electrolysis results with that of the first OR were obtained (data not shown in the present work). Furthermore, the extents of the metal in the reduction products were similar ( $U$ metal, 99.7\%). We also succeeded in separating the reduction product from the reused cathode basket for the second OR run. We cut and observed one inner side (Figure 6(b)) of the emptied STS wire mesh basket (Figure 6(a)) obtained after 


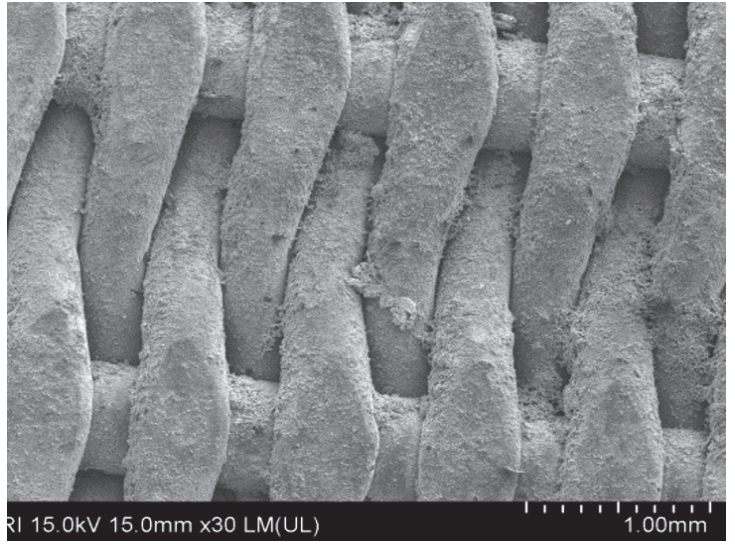

$(\mathrm{a}-1)$

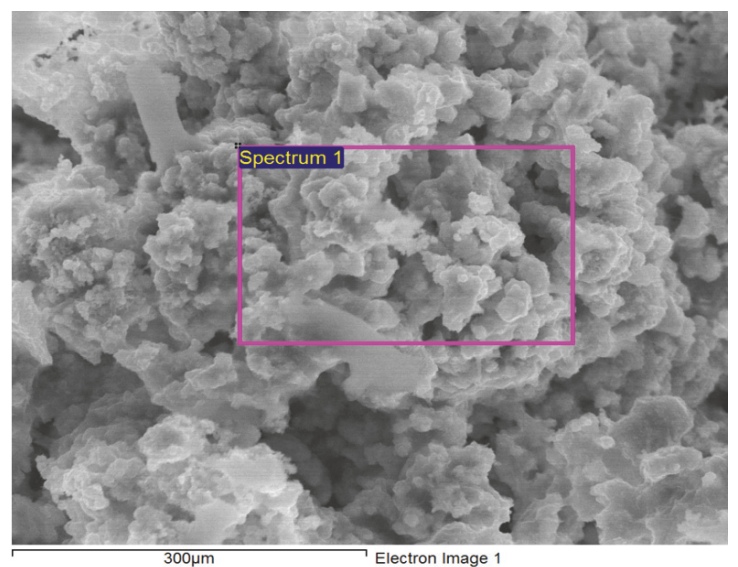

$(\mathrm{a}-2)$

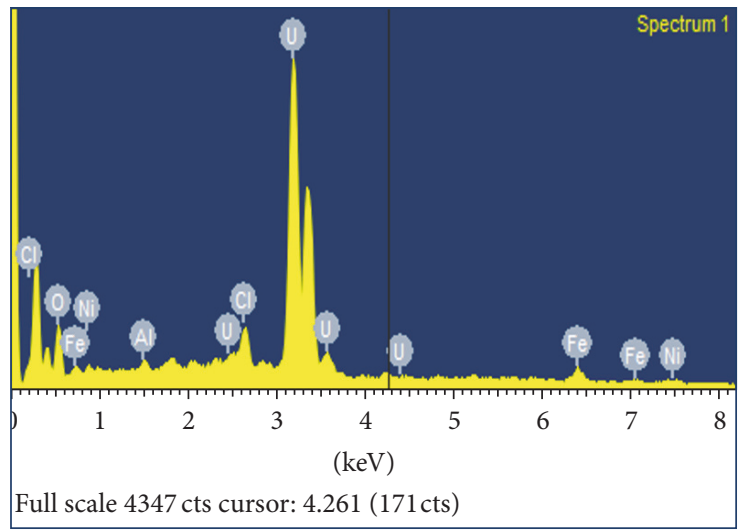

(a-3)

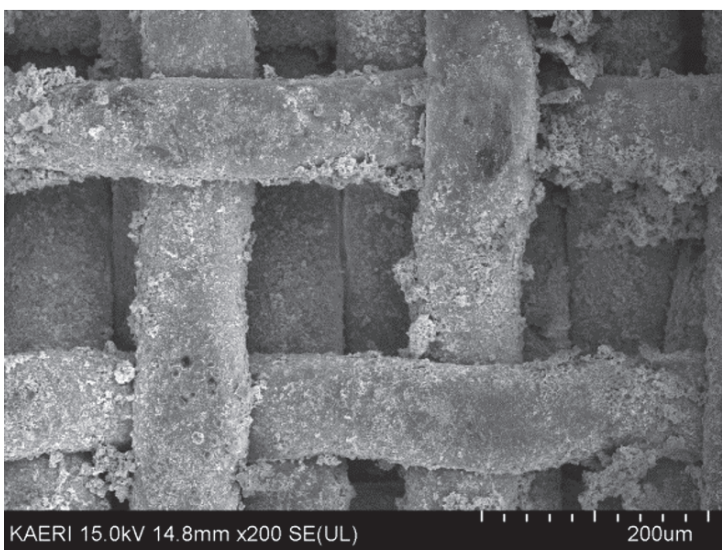

(b-1)

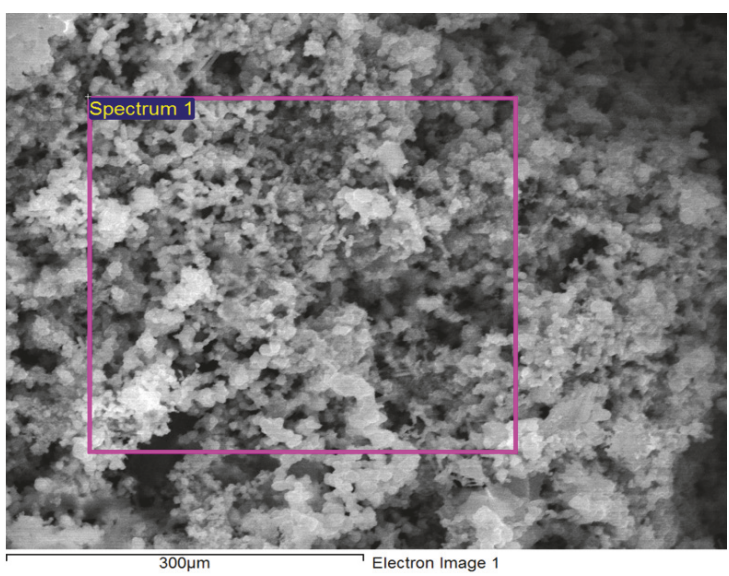

(b-2)

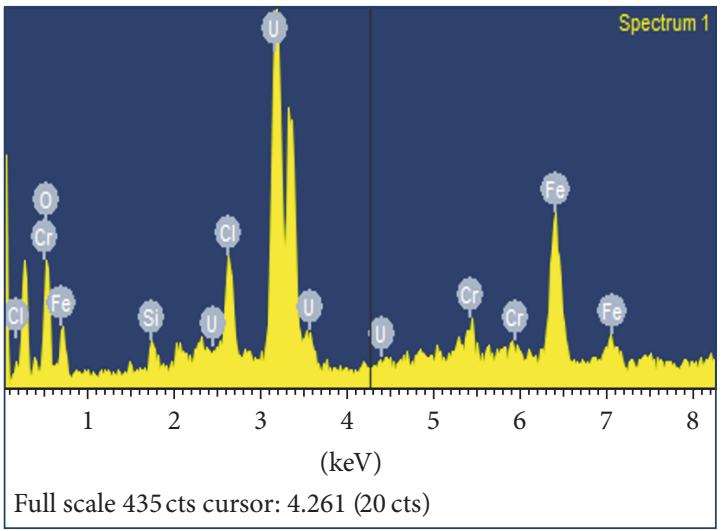

(b-3)

FIGURE 7: Analysis of the cathode basket after the second OR and the subsequent fuel separation via salt draining: (a-1) SEM image of its inner 16 mesh ( $\times 30)$, (a-2) SEM image of the remaining particles on the inner 16 mesh $(\times 10,000)$, (a-3) element identification of the remaining particles using EDX, (b-1) SEM image of its outer 30 mesh $(\times 200)$, (b-2) SEM image of the remaining particles on the outer 30 mesh $(\times 10,000)$, and (b-3) element identification of the remaining particles on the outer mesh using EDX.

the second OR and the subsequent salt drain. It was revealed that none of the reduced simfuel pellets was left inside the cathode basket, except for some fine simfuel powder. The cut STS wire mesh was examined by means of SEM and EDX. Some fine powder (Figure $7(\mathrm{a}-2)$ ) was observed on the inner surface of the cathode basket, where the surface was in contact with reduction product (Figure 7(a-1)). As expected, the EDX analysis results showed that the powder was mainly composed of U. Figure 7(b-1) presents the outer surface of the cathode basket. Unexpectedly, the fine powder was also observed on the wire meshes of the outer surface, in a similar manner to the inner surface. In addition, the 
TABLE 2: Simfuel composition used in this study: each content indicates the surrogate oxides' weight percentages added in the mixture of the surrogate oxides.

\begin{tabular}{lcc}
\hline Group & Surrogate oxides & $\begin{array}{c}\text { Compositions } \\
{[\text { wt.\%] }}\end{array}$ \\
\hline Actinide & $\mathrm{UO}_{2}$ or $\mathrm{UO}_{2.2}$ & 95.33 \\
\hline $\mathrm{Nd}_{2} \mathrm{O}_{3}$ & 0.69 \\
$\mathrm{CeO}_{2}$ & 0.43 \\
Rare earths & $\mathrm{La}_{2} \mathrm{O}_{3}$ & 0.21 \\
& $\mathrm{Pr}_{6} \mathrm{O}_{11}$ & 0.20 \\
$\mathrm{Sm}_{2} \mathrm{O}_{3}$ & 0.14 \\
& $\mathrm{Y}_{2} \mathrm{O}_{3}$ & 0.08 \\
& $\mathrm{Gd}_{2} \mathrm{O}_{3}$ & 0.03 \\
\hline \multirow{3}{*}{ palt-soluble fission } & $\mathrm{BaO}$ & 0.30 \\
& $\mathrm{SrO}$ & 0.13 \\
& $\mathrm{Eu}_{2} \mathrm{O}_{3}$ & 0.02 \\
& $\mathrm{TeO}_{2}$ & 0.09 \\
\hline & $\mathrm{ZrO}_{2}$ & 0.71 \\
Noble metals & $\mathrm{MoO}_{3}$ & 0.74 \\
& $\mathrm{RuO}_{2}$ & 0.59 \\
& $\mathrm{PdO}$ & 0.26 \\
& $\mathrm{Rh}_{2} \mathrm{O}_{3}$ & 0.08 \\
\hline
\end{tabular}

EDX analysis result revealed that the powder was mainly composed of $\mathrm{U}$ and certain elements ( $\mathrm{Fe}$ and $\mathrm{Cr}$ ) from the STS wire mesh (Figure 7(b-3)). As shown in Figure 7(b-2), the grain size observed on the wire meshes of the outer surface is smaller than that on the inner surface. This means that the limited amount of the reduction product with a small size leaked through the open area (the minimum opening size of $40-43 \mu \mathrm{m}$ (Table 1)) of the used the STS wire meshes. The chemical analysis of the bulk $\mathrm{Li}_{2} \mathrm{O}-\mathrm{LiCl}$ salt showed that the concentrations of $\mathrm{U}$ measured after the first and the second OR runs were 33 and $75 \mathrm{ppm}$, respectively. This detection of $\mathrm{U}$ in the salt can be explained by the leakage of the reduction product through the open area of the STS wire meshes. These results suggest that leakage of fuel with a size smaller than the opening size of the STS wire mesh is unavoidable.

\section{Conclusions}

In the present study, a simple separation of the OR reduction product from the STS wire mesh cathode basket was demonstrated only by using the drain of the residual salt. Efficient salt draining was achieved owing to the following reasons: (1) the use of a cathode basket that was made only of permeable STS wire mesh, (2) the small surface area of the used cylindrical porous pellets, and (3) the high temperature of the cathode basket maintained during salt draining. The separation of the reduction product from the STS wire mesh basket is of high importance because it permits the reuse of the basket and the reduction of the process cost and causes fuel loss at the cathode. Moreover, this achievement may enable an integrated process, which would permit direct transfer to electrorefining without conducting the salt distillation process. Furthermore, this approach can be applied not only to the OR process but also to other processes that employ STS wire mesh baskets, such as the ER process.

\section{Conflicts of Interest}

The authors declare that they have no conflicts of interest.

\section{Acknowledgments}

This study was supported by the National Research Foundation of Korea (NRF) grant, funded by the Korean Government (MISP) (2012M2A8A5025697).

\section{References}

[1] J. J. Laidler, J. E. Battles, W. E. Miller, J. P. Ackerman, and E. L. Carls, "Development of pyroprocessing technology," Progress in Nuclear Energy, vol. 31, no. 1-2, pp. 131-140, 1997.

[2] R. W. Benedict and H. F. McFarlane, "EBR-II spent fuel treatment demonstration project status," Radwaste Magazine, vol. 5 , p. 23, 1998.

[3] K. M. Goff, J. C. Wass, K. C. Marsden, and G. M. Teske, "Electrochemical processing of used nuclear fuel," Nuclear Engineering and Technology, vol. 43, no. 4, pp. 335-342, 2011.

[4] K. Nagarajan, B. Prabhakara Reddy, S. Ghosh et al., "Development of pyrochemical reprocessing for spent metal fuels," Energy Procedia, vol. 7, pp. 431-436, 2011.

[5] T. Koyama, Y. Sakamura, M. Iizuka, T. Kato, T. Murakami, and J.-P. Glatz, "Development of pyro-processing fuel cycle technology for closing actinide cycle," Procedia Chemistry, vol. 7, pp. 772-778, 2012.

[6] H.-S. Lee, G.-I. Park, J.-W. Lee et al., "Current status of pyroprocessing development at KAERI," Science and Technology of Nuclear Installations, vol. 2013, Article ID 343492, 11 pages, 2013.

[7] K.-C. Song, H. Lee, J.-M. Hur, J.-G. Kim, D.-H. Ahn, and Y.Z. Cho, "Status of pyroprocessing technology development in Korea," Nuclear Engineering and Technology, vol. 42, no. 2, pp. 131-144, 2010.

[8] H. Lee, J.-M. Hur, J.-G. Kim, D.-H. Ahn, Y.-Z. Cho, and S.W. Paek, "Korean pyrochemical process R\&D activities," Energy Procedia, vol. 7, pp. 391-395, 2011.

[9] E.-Y. Choi and S. M. Jeong, "Electrochemical processing of spent nuclear fuels: An overview of oxide reduction in pyroprocessing technology," Progress in Natural Science: Materials International, vol. 25, no. 6, pp. 572-582, 2015.

[10] L. I. Redey and K. Gourishankar, "Direct electrochemical reduction of metal-oxides," US Patent 6, 540, 902 B1, 2003.

[11] K. Gourishankar, L. Redey, and M. Williamson, "The Minerals, Metals and Materials Society," in The Minerals, Metals and Materials Society, W. Schneider, Ed., Warrendale, Pa, USA, p. 1075, 2002, Light Metals, 2002.

[12] M. Kurata, T. Inoue, J. Serp, M. Ougier, and J.-P. Glatz, "Electrochemical reduction of MOX in LiCl," Journal of Nuclear Materials, vol. 328, no. 2-3, pp. 97-102, 2004.

[13] Y. Sakamura, M. Kurata, and T. Inoue, "Electrochemical reduction of $\mathrm{U} \mathrm{O} 2$ in molten $\mathrm{Ca} \mathrm{Cl} 2$ or LiCl," Journal of the Electrochemical Society, vol. 153, no. 3, pp. D31-D39, 2006. 
[14] Y. Sakamura, T. Omori, and T. Inoue, "Application of electrochemical reduction to produce metal fuel material from actinide oxides," Nuclear Technology, vol. 162, no. 2, pp. 169-178, 2008.

[15] S. M. Jeong, H.-S. Shin, S.-H. Cho, J.-M. Hur, and H. S. Lee, "Electrochemical behavior of a platinum anode for reduction of uranium oxide in a $\mathrm{LiCl}$ molten salt," Electrochimica Acta, vol. 54, no. 26, pp. 6335-6340, 2009.

[16] J.-M. Hur, S. M. Jeong, and H. Lee, "Underpotential deposition of $\mathrm{Li}$ in a molten $\mathrm{LiCl}-\mathrm{Li} 2 \mathrm{O}$ electrolyte for the electrochemical reduction of $\mathrm{U}$ from uranium oxides," Electrochemistry Communications, vol. 12, no. 5, pp. 706-709, 2010.

[17] S. D. Herrmann, S. X. Li, M. F. Simpson, and S. Phongikaroon, "Electrolytic Reduction of Spent Nuclear Oxide Fuel as Part of an Integral Process to Separate and Recover Actinides from Fission Products," Separation Science and Technology, vol. 41, no. 10, pp. 1965-1983, 2006.

[18] S. D. Herrmann, S. X. Li, M. F. Simpson, and J. Nucl, "Electrolytic reduction of spent light water reactor fuel bench-scale experiment results," Journal of Nuclear Science and Technology, vol. 44, no. 3, pp. 361-367, 2007.

[19] S. D. Herrmann and S. X. Li, "Separation and Recovery of Uranium Metal from Spent Light Water Reactor Fuel Via Electrolytic Reduction and Electrorefining," Nuclear Technology, vol. 171, no. 3, pp. 247-265, 2010.

[20] D. Vaden, S. X. Li, B. R. Westphal, K. B. Davies, T. A. Johnson, and D. M. Pace, "Engineering-Scale Liquid Cadmium Cathode Experiments," Nuclear Technology, vol. 162, no. 2, pp. 124-128, 2017.

[21] M. Iizuka, K. Uozumi, T. Ogata, T. Omori, and T. Tsukada, "Development of an innovative electrorefiner for high uranium recovery rate from metal fast reactor fuels," Journal of Nuclear Science and Technology, vol. 46, no. 7, pp. 699-716, 2009.

[22] M. Iizuka, T. Omori, and T. Tsukada, "Behavior of U-Zr Alloy Containing Simulated Fission Products during Anodic Dissolution in Molten Chloride Electrolyte," Journal of Nuclear Science and Technology, vol. 47, no. 3, pp. 244-254, 2010.

[23] T. Kato, T. Inoue, T. Iwai, and Y. Arai, "Separation behaviors of actinides from rare-earths in molten salt electrorefining using saturated liquid cadmium cathode," Journal of Nuclear Materials, vol. 357, no. 1-3, pp. 105-114, 2006.

[24] D. Vaden, S. X. Li, B. R. Westphal, K. B. Davies, T. A. Johnson, and D. M. Pace, "Engineering-scale liquid cadmium cathode experiments," Nuclear Technology, vol. 162, no. 2, pp. 124-128, 2008.

[25] Y. Sakamura and T. Omori, "Electrolytic reduction and electrorefining of uranium to develop pyrochemical reprocessing of oxide fuels," Nuclear Technology, vol. 171, no. 3, pp. 266-275, 2010.

[26] E.-Y. Choi, C. Y. Won, S.-J. Lee et al., "Use of a single fuel containment material during pyroprocessing tests," Annals of Nuclear Energy, vol. 76, pp. 305-314, 2015.

[27] E. Choi, J. Lee, and D. H. Heo, "Electrolytic reduction runs of 0.6 $\mathrm{kg}$ scale-simulated oxide fuel in a $\mathrm{Li}_{2} \mathrm{O}$ - $\mathrm{LiCl}$ molten salt using metal anode shrouds," Journal of Nuclear Materials, vol. 489, pp. 1-8, 2017.

[28] S.-C. Jeon, K.-Y. Lee, J.-W. Lee, Y.-Z. Cho, and D.-H. Ahn, "Scaling up and tailoring the fabrication of UO2 porous pellet with a simulated spent fuel composition," in Proceedings of the International Pyroprocessing Research Conference, Jeju island, Korea, 2016.
[29] S. M. Jeong, H. S. Shin, S. S. Hong, J. M. Hur, J. B. Do, and H. S. Lee, "Electrochemical reduction behavior of U3O8 powder in a LiCl molten salt," Electrochim. Acta, vol. 55, no. 5, pp. 1749-1755, 2010.

[30] W. Park, E.-Y. Choi, S.-W. Kim, S.-C. Jeon, Y.-H. Cho, and J.-M. Hur, "Electrolytic reduction of a simulated oxide spent fuel and the fates of representative elements in a $\mathrm{Li} 2 \mathrm{O}-\mathrm{LiCl}$ molten salt," Journal of Nuclear Materials, vol. 477, pp. 59-66, 2016. 


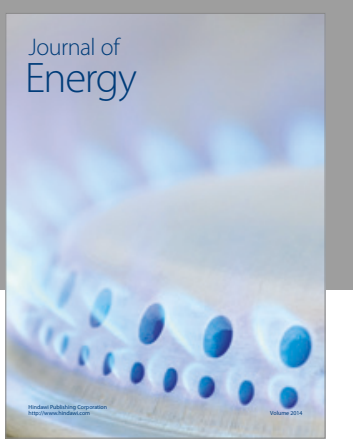

Journal of

Industrial Engineering
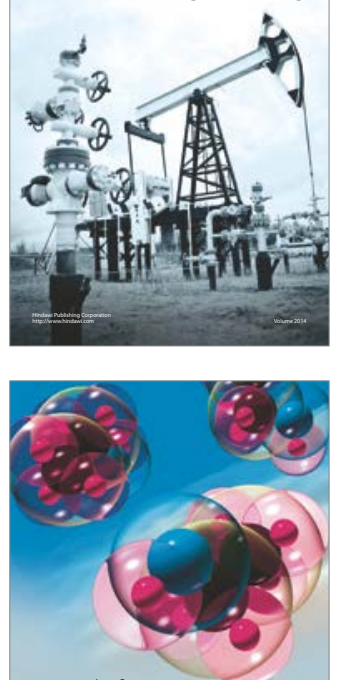

Fuels
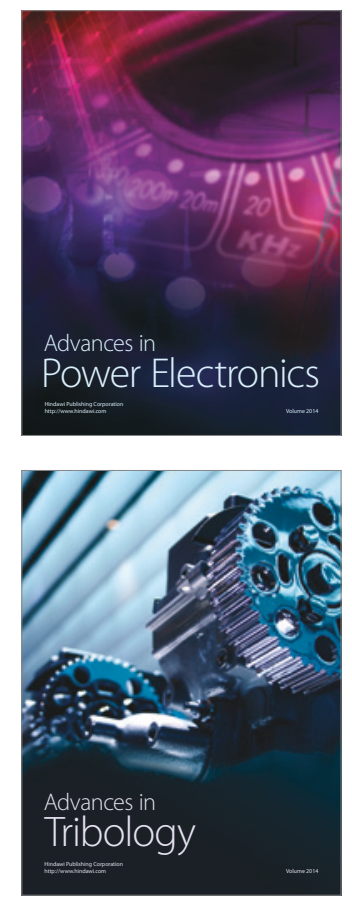
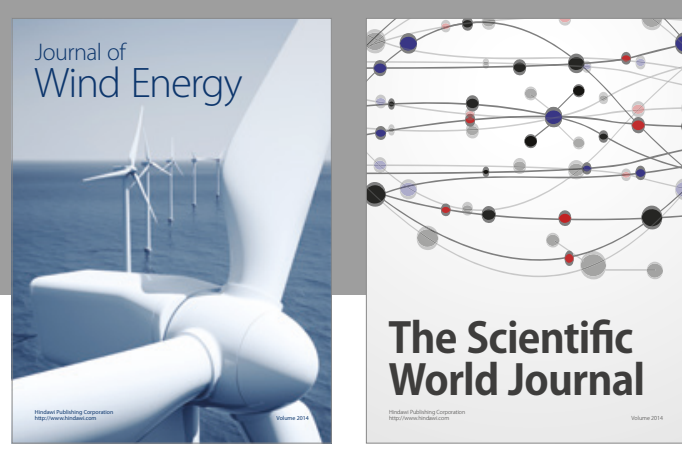

The Scientific World Journal
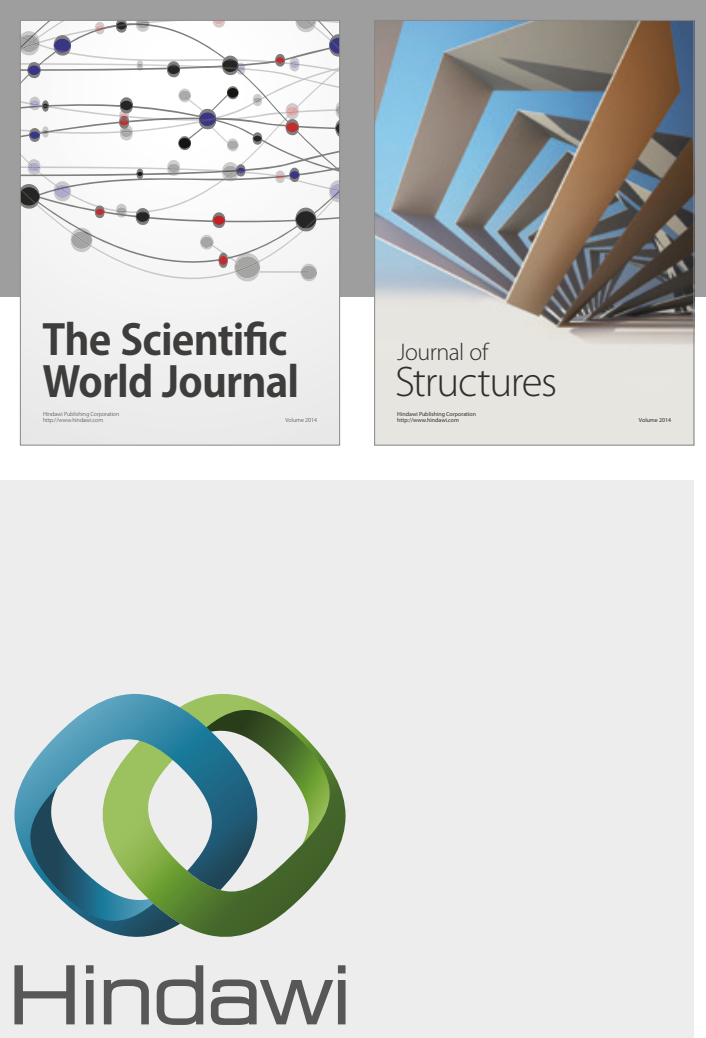

Submit your manuscripts at

https://www.hindawi.com
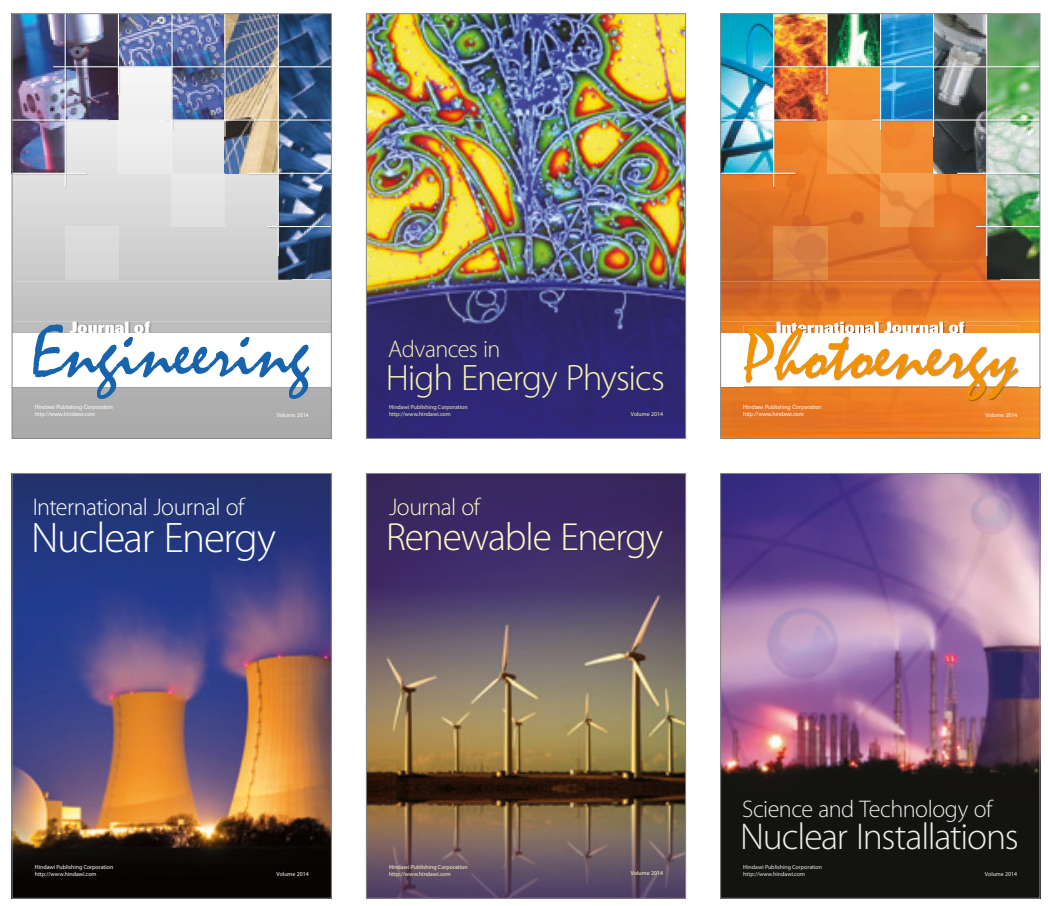

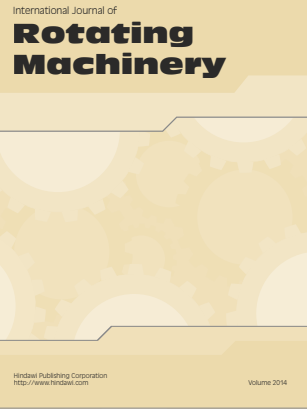

Journal of

Petroleum Engineering

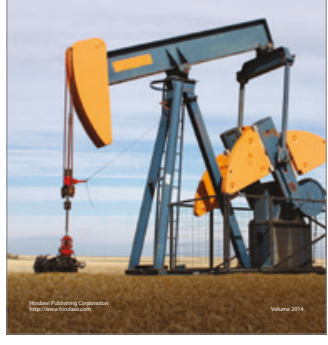

Journal of
Solar Energy
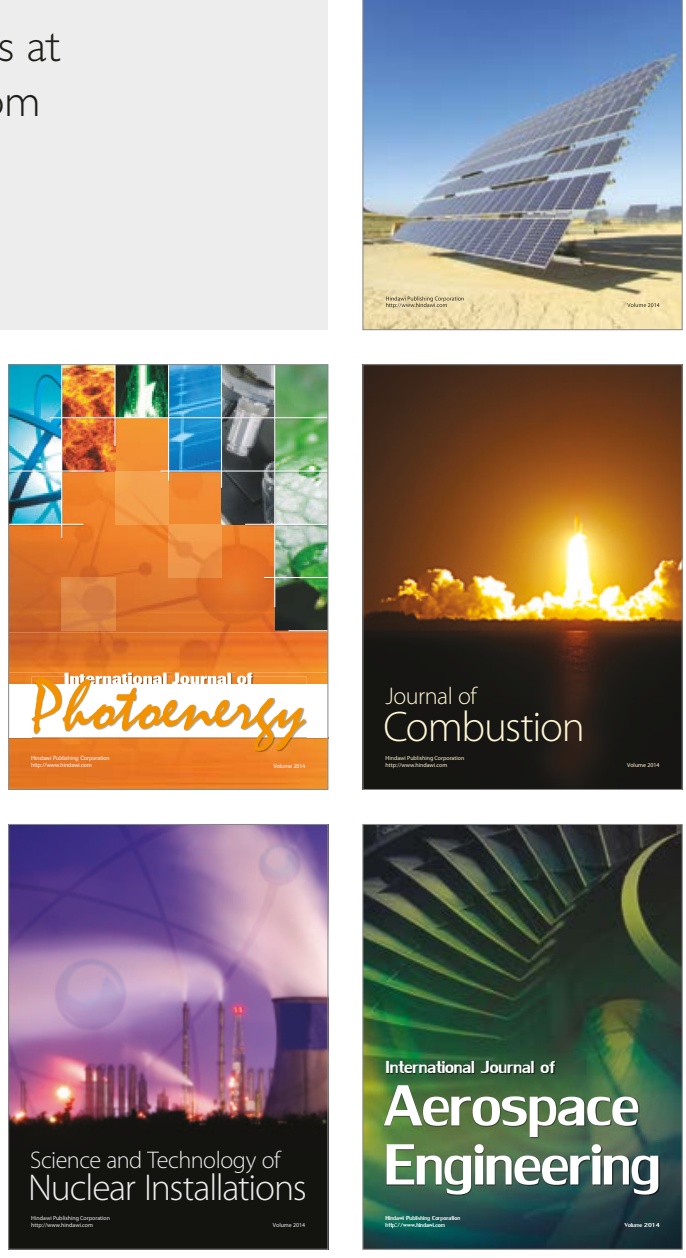